\title{
Self-reported oral health in the Dutch 100-plus Study of cognitively healthy centenarians: an observational cohort study
}

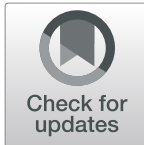

Nina Beker ${ }^{1 \dagger}$, Claar D. van der Maarel-Wierink ${ }^{2,3 \dagger}$, Cees de Baat ${ }^{2,4}$ and Henne Holstege ${ }^{1,5^{*}}$

\begin{abstract}
Background: Due to improved healthcare, more people reach extreme ages. Oral health in the oldest-old has thus far been poorly described. Here, we investigated self-reported oral health factors, use of professional oral health care, and associations with clinical measures in centenarians considered cognitively healthy.

Methods: In this observational cohort study, we included 162 (74\% female) centenarians from the Dutch 100-plus Study cohort who self-reported to be cognitively healthy, as confirmed by a proxy. Centenarians were questioned about their physical well-being including medication use and their cognitive functioning was evaluated using the Mini-Mental State Examination. Questions regarding oral health included preservation of teeth, oral pain or discomfort, chewing ability, xerostomia, and time since last visit to an oral health care provider. Associations between oral health and clinical measures were investigated with ordinal logistic or linear regression analyses, adjusted for gender, age, and education.
\end{abstract}

Results: The majority of the centenarians indicated to have good oral health: $76 \%$ felt no oral pain/discomfort, $65 \%$ indicated to chew well; while only $18 \%$ had symptoms of xerostomia. Of all centenarians, $83 \%$ were edentulous and were wearing removable complete maxillary and mandibular dental prostheses, $1 \%$ was edentulous with no dental prosthesis, while $16 \%$ was dentate with or without removable partial dental prostheses (10 and 6\% respectively). Dentate and edentulous centenarians experienced similar levels of oral pain and/or discomfort, chewing ability, xerostomia, and their cognitive functioning was similar. No relationship between cognitive functioning and chewing ability was found. Xerostomia was associated with medication use $(p=.001)$, which mostly regarded medications for cardiovascular diseases, diuretics, anti-coagulants, and antacids. Only $18 \%$ of the centenarians visited an oral health care provider during the year prior to the interview, of whom $48 \%$ were dentate centenarians. Notably, $49 \%$ of the centenarians had not visited an oral health care provider for $\geq 10$ years.

Conclusions: Most centenarians were edentulous and did not report oral complaints. Less than one-fifth of the centenarians continued to seek regular professional oral health care. Since the proportion of dentates in the oldestold will increase in the near future, a proactive attitude toward this group is necessary.

Keywords: Oral health, 100-plus study, Centenarians, Longevity, Oldest-old

\footnotetext{
* Correspondence: h.holstege@amsterdamumc.nl

${ }^{+}$Nina Beker and Claar D. van der Maarel-Wierink contributed equally to this

work.

${ }^{1}$ Alzheimer Center Amsterdam, Department of Neurology, Amsterdam

Neuroscience, Vrije Universiteit Amsterdam, Amsterdam UMC, PO Box 7057,

Amsterdam 1007 MB, The Netherlands

${ }^{5}$ Department of Clinical Genetics, Amsterdam Neuroscience, Vrije Universiteit

Amsterdam, Amsterdam UMC, Amsterdam, The Netherlands

Full list of author information is available at the end of the article
}

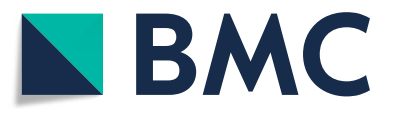

(c) The Author(s). 2019 Open Access This article is distributed under the terms of the Creative Commons Attribution 4.0 International License (http://creativecommons.org/licenses/by/4.0/), which permits unrestricted use, distribution, and

reproduction in any medium, provided you give appropriate credit to the original author(s) and the source, provide a link to the Creative Commons license, and indicate if changes were made. The Creative Commons Public Domain Dedication waiver (http://creativecommons.org/publicdomain/zero/1.0/) applies to the data made available in this article, unless otherwise stated. 


\section{Background}

Worldwide, the number of centenarians is estimated to increase eighteen fold by 2050, up to 3.2 million [1]. In the Netherlands, the number of centenarians is expected to double in the next twenty years [2]. Oral health has been shown to be an important predictor of longevity [3]. An unhealthy dentition increases the risk of oral inflammation, which associates with poor health and decreased life expectancy [4]. After controlling for life-style behaviors and health condition, the risk of all-cause mortality correlates with the number of natural teeth present, suggesting that the 5-year survival rate increased by $4 \%$ per retained tooth beyond the age of 70 years [5]. Other studies indicate that masticatory activity is a prerequisite for maintaining adequate cognitive functions $[6,7]$.

Factors with a potential negative effect on oral health are: no regular dental consultations and hyposalivation, often a consequence of medication use $[8,9]$. This indicates that these factors should be considered when evaluating oral health.

Due to increasing longevity resulting from developments in general medical and oral health care, the number of dentate older people increases [10]. In fact, between 2000 and 2009, the fraction of the population in the Netherlands above 65 years wearing removable complete maxillary and mandibular dental prostheses decreased from 59 to $41 \%$ [11]. However, little is known about the oral health of people who reach extreme ages in cognitive health and to what extent they reach out to oral health care providers.

Here, we aim to describe the oral health and use of professional oral health care self-reported by cognitively healthy Dutch centenarians. In addition, we investigate associations between factors of oral health and use of prescription medications, cognitive functioning and independence in activities of daily living (ADL).

\section{Methods}

\section{Study design, setting and participants}

We investigated self-reported oral health in a subset of the centenarians included in the 100-plus Study. The 100-plus Study is an observational cohort study of Dutch centenarians (age $\geq 100$ years) who self-report to be cognitively healthy, which is confirmed by a family member or caregiver. Centenarians were recruited by different media and mouth-to-mouth advertisement, as described previously [12]. Centenarians who were included between January 2013 and January 2016, $(n=162)$, were presented the oral health questionnaire. Visits took place at the home residence of the centenarians by trained researches with a neuropsychological and/or medical background.

\section{Data collection}

Participants were interviewed about their (medical) history, lifestyle behavior and, current physical well-being including medication use [12]. Prescription medications were classified according to eleven medicationcategories: cardiac medication, diuretics, anti-coagulants, laxatives, antacids, analgesic, sedatives, antidiabetics, antidepressants, iron supplements, and other. For each centenarian, we calculated the total number of categories for which they used at least one medication. Education level was categorized according to the International Standard Classification of Education 1997 (ISCED) [13]. Independence in activities of daily living (ADL) was assessed using the 10-item Barthel Index (BI) [14], with scores ranging from 0 to 20 ; scores $<15$ indicate dependency and scores $\geq 15$ indicate independence [15]. To assess cognitive functioning, we administered the MiniMental State Examination (MMSE) [16]: with scores ranging from 0 to 30; higher scores indicate better cognitive functioning [17]. We used multiple imputation to impute scores for missing items on the MMSE test attributable to vision and hearing disability [12]. In case less than $20 \%$ of the items were missing, we imputed total scores on the BI using mean imputation methods.

During the interview, centenarians were questioned about components of oral health which included the preservation of teeth, oral pain or discomfort, chewing ability, and xerostomia. We were informed about use of professional oral health care by asking the centenarians for the time period since the last visit to an oral health care provider; see Table 1 for the questionnaire. Xerostomia was assessed using the modified xerostomia questionnaire [18]; scores $\geq 8$ indicated xerostomia.

\section{Analyses}

Statistical analyses were performed using MASS package in $\mathrm{R}$ ( $\mathrm{v}$ 3.5.2) (The R Foundation, https://www.r-project. org/). We investigated associations between oral health and clinical measures with ordinal logistic regression analyses for ordinal outcome variables and linear regression analyses for continuous outcome variables, adjusted for gender, age, and education. Statistics were presented by odds ratios (OR) or betas and 95\% confidence intervals. A $p$-value of 0.05 was considered statistically significant.

\section{Results}

Demographic, clinical and oral health characteristics

In total, 354 centenarians were approached by January 2016, of whom 46 were not eligible because of cognitive impairment, 54 had no interest in participating, 26 found it too burdensome, 16 were deceased and 50 centenarians were not included for other or unknown reasons. 
Table 1 Questionnaire including the various components of oral health

Questions
Do you have:
natural teeth
natural teeth in combination with a removable partial denture
removable complete dentures
no natural teeth, no removable dentures
What is the time period since your last visit to an oral health care
provider?
Less than one year
1-5 year(s)
$5-10$ years
10-20 years
Do you experience pain or discomfort in your mouth?
Yes
No
Sometimes
Are you able to chew adequately?
Yes
Rather good
Poor
No
Which option does apply to your situation?*
My mouth feels dry when eating
My mouth feels dry
I have difficulty eating dry foods
I have difficulties swallowing certain foods
My lips feel dry

*Xerostomia questionnaire. Reply on this questionnaire can be: "never" = 1, "sometimes" $=2$, "always" $=3$. A total sumscore $<8$ indicates no xerostomia, a total sumscore $\geq 8$ indicates xerostomia

The 162 centenarians we investigated were born between 1902 and 1915; 74\% were women, and 52\% were educated at a medium level or higher. $50 \%$ of the centenarians were community-dwelling, $69 \%$ were mobile with or without aids, or with assistance of another person. Most centenarians were ADL independent (BI score $\geq 15$ : $49 \%$ vs BI score $<15$ : $38 \%$ ) and had high cognitive functioning (median [IQR] MMSE score: 26 [23-28]). More clinical descriptives of this cohort of centenarians are represented in Table 2.

\section{Oral health characteristics and use of professional oral health care}

The large majority of the centenarians ( $n=134,83 \%)$, were edentulous and were wearing removable maxillary and mandibular complete dental prostheses; 2 centenarians $(1 \%)$ were edentulous and did not wear removable complete dental prostheses; 10 centenarians $(6 \%)$ were fully dentate and did not wear removable partial dental prostheses; $16(10 \%)$ were dentate and were wearing one or two removable partial dental prostheses. By selfreport, 123 centenarians (76\%) did not experience oral pain or discomfort; 106 (65\%) could chew adequately; for 30 centenarians (18\%) xerostomia was assessed (by a score $\geq 8$ on the xerostomia questionnaire).

Twenty-nine centenarians (18\%) had visited an oral health care provider during the year prior to the interview, while 79 centenarians (49\%) had not visited an oral health care provider for at least 10 years prior to the interview (Table 2).

\section{Self-reported oral health in dentate and edentulous centenarians}

Participants were stratified as follows: (1) dentate with or without removable partial dental prostheses, denoted dentate centenarians, $n=26$ (16\%); (2) edentulous and wearing removable complete maxillary and mandibular dental prostheses, denoted edentulous centenarians, $n=$ 134 (83\%). The two edentulous centenarians who did not wear removable complete maxillary and mandibular dental prostheses were excluded from analyses on differences between these groups. Dentate and edentulous centenarians experienced similar levels of oral pain and/ or discomfort $(p=809)$, and their chewing ability and xerostomia scores were similar $(p=.896$ and $p=.877$ respectively, Table 3$)$. Both groups had similar levels of cognition $(p=.753)$, and we observed no relationship between chewing ability and cognitive functioning $(p=.623)$ (Table 3).

\section{Use of professional oral health care, preservation of teeth, and ADL independence}

The majority $(64 \%)$ of the dentate centenarians had visited an oral health care provider less than 1 year prior to the interview. In contrast, the majority (59\%) of the edentulous centenarians had not visited an oral health care provider for at least 10 years prior to the interview. Indeed, $48 \%$ of the centenarians who had regularly visited an oral health care provider was dentate (14/29). While consulting an oral health care provider was associated with being dentate $(p<.001)$, it was not associated with ADL independence $(p=.734)$. Centenarians who visited an oral health care provider $0-5$ years ago, had similar levels of oral pain or discomfort $(p=.539)$, chewing ability $(p=.138)$, and xerostomia $(p=.256)$ compared to centenarians who visited an oral health care provider more than 5 years ago prior to the interview.

\section{Xerostomia, gender, and use of prescription medications} Xerostomia scores did not differ between males and females $(p=.506$, Table 3$)$. However, centenarians who had symptoms of xerostomia, used significantly more prescription medication compared to centenarians who had no symptoms of xerostomia $(B=1.41$ [95\% CI: 0.61-2.20], $p=.001$ ), Table 3). Medications that were most frequently used included cardiac medication, 
Table 2 Clinical and demographic characteristics (total $n=162$ )

Age, median (IQR)

Gender, female N (\%)

Education, N (\%)

Low

Medium

High

Missing value

Cognitive functioning, MMSE, median (IQR) ${ }^{\mathrm{a}}$

Missing value, N (\%)

Living situation, $N(\%)$

Community-dwelling, or independent in a residence with available services

Fulltime assistance at home residence

In a residential care center

In a nursing home

With family

Missing value

Independence in $\mathrm{ADL}, \mathrm{BI}$ median $(\mathrm{IQR})^{\mathrm{b}}$

Independent (scores $\geq 15$ ), N (\%)

Dependent (scores < 15), N (\%)

Missing value

Mobility, N (\%)

Able to walk independently, with or without a walking stick or walker

Able to walk with help of another person

Able to move independently in a wheelchair

Not able to move independently in a wheelchair

Missing value

Prescription medication categories, median (IQR)

Cardiac medication, N (\%)

Diuretics, N (\%)

Anti-coagulants, N (\%)

Antacids, N (\%)

Analgesic, N (\%)

Sedatives, N (\%)

Laxatives, N (\%)_

Antidiabetics, N (\%)

Antidepressants, N (\%)

Iron supplements, N (\%)

Other, N (\%)

Missing value

Disease history, yes N (\%)

Cardiovascular disease

Musculoskeletal disease

Sensory problems

Cancer

Autoimmune disease
$100.9(100.2-102.1)$

$120(74)$

76 (47)

$62(38)$

23 (14)

1 (1)

$26(23-28)$

8 (5)

$82(50)$

3 (2)

$67(41)$

3 (2)

$6(4)$

1 (1)

15 (11-19)

79 (49)

61 (38)

$22(13)$

$112(69)$

$11(7)$

$11(7)$

9 (5)

19 (12)

$3(5-7)$

$86(53)$

76 (47)

$73(45)$

$66(41)$

$41(25)$

26 (16)

29 (18)

8 (5)

4 (3)

$11(7)$

80 (49)

$10(6)$

86 (53)

69 (43)

49 (30)

30 (19)

$10(6)$ 
Table 2 Clinical and demographic characteristics (total $n=162$ ) (Continued)

\begin{tabular}{|c|c|}
\hline Other & $63(39)$ \\
\hline Missing value & $55(34)$ \\
\hline \multicolumn{2}{|l|}{ Preservation of teeth, N (\%) } \\
\hline Edentulous/no removable complete dental prostheses & $2(1)$ \\
\hline Dentate without removable partial dental prosthesis & $10(6)$ \\
\hline Dentate with removable partial dental prosthesis & $16(10)$ \\
\hline Edentulous and removable complete dental prostheses & $134(83)$ \\
\hline \multicolumn{2}{|l|}{ Oral pain or discomfort, N (\%) } \\
\hline No & $123(76)$ \\
\hline Sometimes & $13(8)$ \\
\hline Yes & $7(4)$ \\
\hline Missing value & $19(12)$ \\
\hline \multicolumn{2}{|l|}{ Chewing ability, N (\%) } \\
\hline Good & $106(65)$ \\
\hline Rather good & $23(14)$ \\
\hline Poor & $10(6)$ \\
\hline Not able & $3(2)$ \\
\hline Missing value & $20(13)$ \\
\hline Xerostomia, median $(\mathrm{IQR})^{\mathrm{C}}$ & $6(5-7)$ \\
\hline Yes (scores $\geq 8), \mathrm{N}(\%)$ & $30(18)$ \\
\hline No (scores < 8), N (\%) & $108(67)$ \\
\hline Missing value & $24(15)$ \\
\hline \multicolumn{2}{|l|}{ Time period since last visit to an oral health care provider, N (\%) } \\
\hline Less than 1 year & $29(18)$ \\
\hline 1 to 5 years & $29(18)$ \\
\hline 5 to 10 years & $14(8)$ \\
\hline More than 10 years & $79(49)$ \\
\hline Missing value & $11(7)$ \\
\hline
\end{tabular}

Values are presented by number $(\mathrm{N})$ and percentage (\%) or median and IQR. ${ }^{\mathrm{a}}$ Score range of the MMSE: 0 to 30 . Higer scores indicate better performance. ${ }^{b}$ Score range of the Barthel Index: 0 to 20 . Higher scores indicate more independency in ADL. 'Score range of the xerostomia questionnaire: 5 to 15 . Higher scores indicate more xerostomia symptoms. BI=Barthel Index. MMSE = Mini-Mental State Examination. $A D L=A c t i v i t i e s$ of daily living. IQR $=$ Interquartile range. $\mathrm{SD}=$ Standard Deviation

diuretics, anti-coagulants, and antacids (respectively 53, 47,45 and $41 \%$ of the centenarians).

\section{Discussion}

Here we described the self-reported oral health and frequency of oral health care visits in a unique cohort of 162 self-reported cognitively healthy centenarians in the Netherlands. The large majority (83\%) of the centenarians were edentulous and were wearing removable complete maxillary and mandibular dental prostheses. We assume that many of the centenarians in this study have been wearing these dental prostheses for several decades. This may have led to severe atrophy of the edentulous alveolar ridges and consequently often to oral pain and discomfort. Surprisingly, $76 \%$ of the participants within the total sample did not experience any oral pain or discomfort while $49 \%$ had not visited an oral health care provider for at least 10 years.

The fraction of edentulous centenarians in the 100plus Study cohort was higher than the edentulous centenarians from the New England Centenarian Study (NECS) [19]: $83 \%$ vs 37\%. The NECS studied the oral health of 64 centenarians, of these, 35\% retained more than half of the total number of natural teeth, $29 \%$ had retained less than half of the total number of natural teeth, and $67 \%$ wore removable complete or partial dental prosthesis. This difference between the two centenarian cohorts may be explained by the fact that the edentulousness in older adults in de United States is 20$30 \%$ lower compared to the Netherlands [20]. The fraction of edentulous 65-74 year-olds in the United States decreased from $45 \%$ in $1971-1974$ to an estimated $24 \%$ 


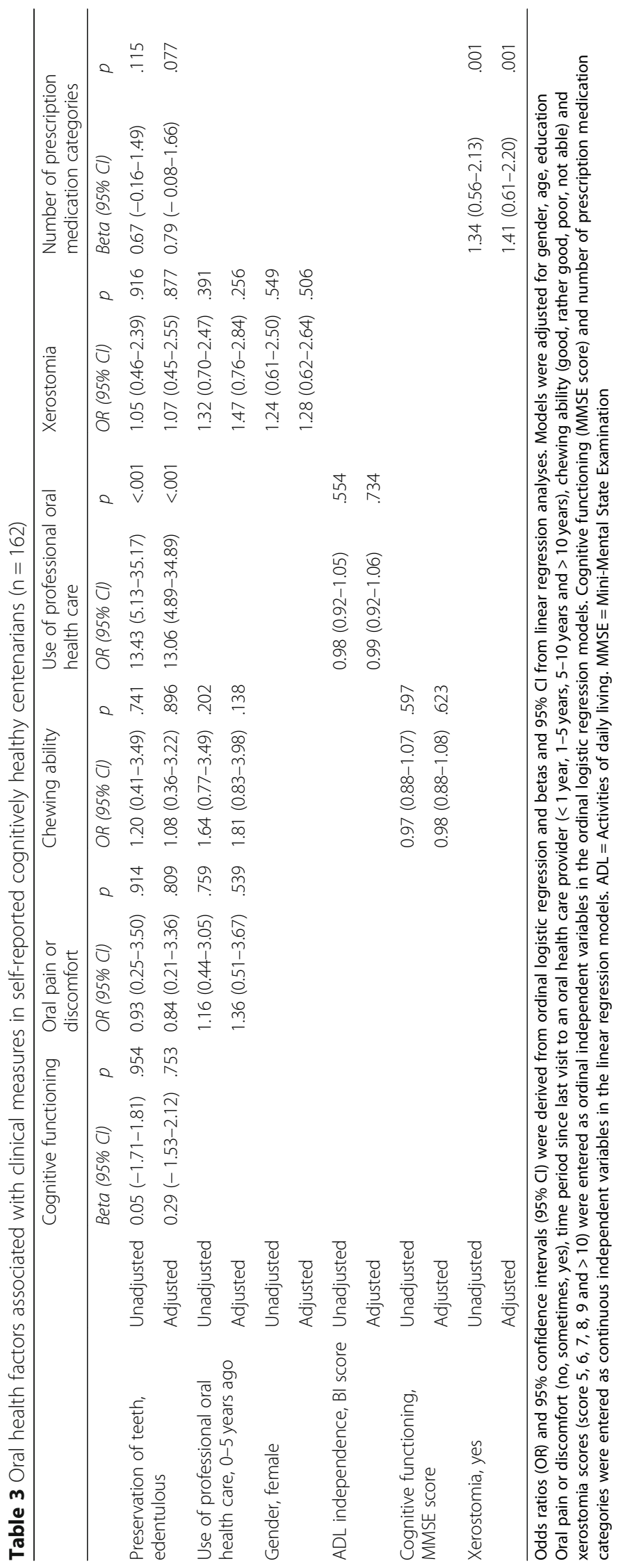


in 1999-2004 [20]. By comparison, a 2009 survey in the Netherlands estimated that $41 \%$ of the people aged $\geq 65$ years was edentulous [11], compared to $61 \%$ of the 80-year-olds in a community-dwelling sample in 2015 [21].

Between the ages of 60 and 70 years, the nowcentenarians from the NECS had lower rates of edentulousness than their generation peers, suggesting that they had a better oral health during adulthood [19]. Reports indicated that people from the higher socioeconomic classes have better oral health, both in the United States and the Netherlands [22]. Indeed, the centenarians from the NECS came from higher socioeconomic classes. The centenarians from the 100-plus Study also came from higher socio-economic classes compared to their birth generation [12], and although we did not address retrospective oral health in our questionnaire, we might expect that they also had a better oral health during adulthood [12]. This may be further supported by the finding that the fraction of individuals who experienced xerostomia is considerably lower in the centenarians compared to home-dwelling 60-80-yearolds in the Netherlands ( $18 \%$ vs $43 \%$, albeit that oral health questionnaires were different) [23]. Of note, the centenarians who did report symptoms of xerostomia used more prescription medication than those who did not suffer from symptoms of xerostomia [8].

Within our cohort, dentate and edentulous centenarians reported similar chewing ability, similar levels of oral pain or discomfort and xerostomia scores. The selfreported absence of oral pain or discomfort may be influenced by the optimistic nature of centenarians from the 100-plus Study [12]; centenarians across populations are more likely to be agreeable and conscientious individuals, and they may be less likely to complain [24-26]. Although we could not test this, we speculate that centenarians might avoid chewing problems or oral discomfort by preferring softer foods. In this group, we could not replicate the association between masticatory (chewing) activity and cognitive functioning as found by others $[5,7]$. The inclusion criteria of the 100-plus Study include being cognitively healthy, which may obscure any relation between cognitive function.

Half of the edentulous centenarians had not visited an oral health care provider for at least 10 years prior to the interview, this is in line with the observation that $69 \%$ of the home-dwelling older adults in the Netherlands who received formal home care, had not consulted an oral health care provider since many years [27]. Older people seem to favor long-established oral hygiene routines, but with increasing frailty they fail to continue their usual oral health care behavior and stop consulting oral health care providers [28]. However, in this selected cohort of centenarians, we did not find an association between dental consultation and the level of dependency in ADL.

Although most of the centenarians within the 100-plus Study cohort were edentulous, the number of dentate centenarians will increase in the near future [11, 29]. Given our findings that dentate centenarians tend to seek more oral health care, policy makers and educators should be we aware of an increasing need for oral health care in the oldest-old. Dutch oral health care providers might at present not be capable and appropriately trained to meet these changing needs of the population. As a first step, researchers in collaboration with clinicians from the Netherlands and Belgium, now established a research agenda 'Oral care for elderly', which aims to conduct more research in this area and to expand and implement newly acquired knowledge in the near future [30].

\section{Limitations and future studies}

We acknowledge that oral health of centenarians should ideally be objectively assessed by an oral health care provider. It might be that undetected types of oral pathology may be present beneath dental prostheses or in other parts of the oral cavity. Dental caries of periodontal disease may exist in the dentate group, but not cause pain or discomfort. Future studies including an oral health care check-up by an oral health care provider would allow the assessment of the quantity and quality of their saliva, which is important for the protection of oral health [8]. We note that this centenarian cohort represents a high-performing sub-selection of cognitively healthy Dutch centenarians, such that our findings may not be representative for the general centenarian population in the Netherlands.

\section{Conclusions}

The large majority of the centenarians in the current study were edentulous and had not consulted an oral health care provider since many years. However, few centenarians complained of oral discomfort, pain or xerostomia, which may in part be influenced by the optimistic nature of this group. The number of dentates in the oldest-old is expected to increase in the near future. To provide suitable oral health care for the oldest-old, providers should be aware that an increasing amount of centenarians will need professional oral health care in the future.

\section{Abbreviations}

ADL: activities of daily living; BI: Barthel Index; ISCED: International Standard Classification of Education; MMSE: Mini-Mental State Examination; NECS: New England Centenarian Study

\section{Acknowledgements}

We are grateful for the collaborative efforts of all participating centenarians and their family members and/or relations. We acknowledge the people 
who visited and/or recruited the centenarians. We thank Sietske Sikkes and Marc Hulsman for their advice on the analyses performed in this manuscript and Philip Scheltens and Elizabeth Wemmenhove for their involvement in the design of the project.

\section{Authors' contributions}

NB and CM contributed equally to the manuscript, including the study concept, analysis and interpretation of the data and drafting of the manuscript. $\mathrm{HH}$ contributed to the study concept and design, the critical revision of the manuscript and to the acquisition of data together with NB. CB was involved with the study concept and critical revision of the manuscript. All authors read and approved the final version of the manuscript.

\section{Funding}

This work was supported by Stichting Alzheimer Nederland (WE09.2014-03), Stichting Dioraphte (VSM 1404 1402) and Stichting VUmc Fonds. Research of the Alzheimer center Amsterdam is part of the neurodegeneration research program of Amsterdam Neuroscience.

\section{Availability of data and materials}

The datasets used and/or analyzed during the current study are available from the corresponding author on reasonable request.

\section{Ethics approval and consent to participate}

This study was approved by the Medical Ethical Committee of the Amsterdam UMC Medical Centers (reference number: 2016.440) and all participants provided written informed consent. The study has been conducted in accordance with the declaration of Helsinki.

\section{Consent for publication}

Not applicable.

\section{Competing interests}

The authors declare that they have no competing interests.

\section{Author details}

${ }^{1}$ Alzheimer Center Amsterdam, Department of Neurology, Amsterdam Neuroscience, Vrije Universiteit Amsterdam, Amsterdam UMC, PO Box 7057, Amsterdam 1007 MB, The Netherlands. ${ }^{2}$ BENECOMO, Flemish-Netherlands Geriatric Oral Research Group, Ghent, Belgium and Amsterdam, The Netherlands. ${ }^{3}$ Center for Special Care in Dentistry, Amsterdam, The Netherlands. ${ }^{4}$ Department of Oral Function and Prosthetic Dentistry, Radboud University Medical Center, Nijmegen, The Netherlands. ${ }^{5}$ Department of Clinical Genetics, Amsterdam Neuroscience, Vrije Universiteit Amsterdam, Amsterdam UMC, Amsterdam, The Netherlands.

\section{Received: 20 May 2019 Accepted: 19 November 2019} Published online: 18 December 2019

\section{References}

1. United Nations. Department of Economic and Social Affairs. Profiles of Ageing 2019. Population Division (PO/DB/PD/WPA/2019). Retrieved from https://www.un.org/en/development/desa/population/index.asp.

2. Central Bureau for Statistics. Statistics Netherlands: Centenarian population will be doubled in the next 20 years. 2017. Retrieved from https://www.cbs. nl/nl-nl/nieuws/2017/20/aantal-100-plussers-verdubbeld-in-20-jaar

3. Centers for Disease Control and Prevention (CDC). Public health and aging: retention of natural teeth among older adults-United States, 2002. MMWR Morb Mortal Wkly Rep. 2003;52(50):1226.

4. Seitz MW, Listl S, Bartols A, Schubert I, Blaschke K, Haux C, et al. Current knowledge on correlations between highly prevalent dental conditions and chronic diseases: an umbrella review. Prev Chronic Dis. 2019;16:E132.

5. Hirotomi T, Yoshihara A, Ogawa H, Miyazaki H. Number of teeth and 5-year mortality in an elderly population. Community Dent Oral Epidemiol. 2015; 43(3):226-31.

6. Weijenberg RA, Lobbezoo F, Knol DL, Tomassen J, Scherder EJ. Increased masticatory activity and quality of life in elderly persons with dementia--a longitudinal matched cluster randomized single-blind multicenter intervention study. BMC Neurol. 2013;13:26.
7. Weijenberg RA, Scherder EJ, Lobbezoo F. Mastication for the mind--the relationship between mastication and cognition in ageing and dementia. Neurosci Biobehav Rev. 2011;35(3):483-97.

8. Wolff A, Joshi RK, Ekström J, Aframian D, Pedersen AML, Proctor G, et al. A guide to medications inducing salivary gland dysfunction, xerostomia, and subjective sialorrhea: a systematic review sponsored by the world workshop on Oral medicine VI. Drugs in R\&d. 2017;17(1):1-28.

9. Aliko A, Wolff A, Dawes C, Aframian D, Proctor G, Ekstrom J, et al. World workshop on Oral medicine Vl: clinical implications of medication-induced salivary gland dysfunction. Oral Surg Oral Med Oral Pathol Oral Radiol. 2015; 120(2):185-206

10. Petersen PE, Kandelman D, Arpin S, Ogawa H. Global oral health of older people--call for public health action. Community Dent Health. 2010;27(4 Suppl 2):257-67.

11. Central Bureau for Statistics. Statistics Netherlands: Health, lifestyle, use of healthcare; 2000-2009. 2016. Retrieved from https://opendata.cbs.nl/statline/ \#/CBS/nl/dataset/03799/table?fromstatweb.

12. Holstege $H$, Beker N, Dijkstra T, Pieterse $K$, Wemmenhove E, Schouten $K$, et al. The 100-plus study of cognitively healthy centenarians: rationale, design and cohort description. Eur J Epidemiol. 2018.

13. UNESCO United Nations Educational, Scientific and Cultural Organization. International Standard Classification of Education, ISCED 1997. 2003. Available at http://www.unesco.org/education/.

14. Mahoney F, Barthel D. Functional evaluation: The Barthel Index. Maryland State Medical Journal. 1965;12:61-65.

15. Post MWM, Van Asbeck FWA, Van Dijk AJ, Schrijvers AJP. Nederlandse interviewversie van de Barthel-index onderzocht bij dwarslaesiepatienten. Ned Tijdschr Geneeskd. 1995;139:1376.

16. Folstein MF, Folstein SE, McHugh PR. "Mini-mental state". A practical method for grading the cognitive state of patients for the clinician. J Psychiatr Res. 1975;12(3):189-98.

17. Kahle-Wrobleski K, Corrada MM, Li B, Kawas CH. Sensitivity and specificity of the mini-mental state examination for identifying dementia in the oldestold: the 90+ study. J Am Geriatr Soc. 2007;55(2):284-9.

18. Thomson WM, van der Putten GJ, de Baat C, Ikebe K, Matsuda K, Enoki K, et al. Shortening the xerostomia inventory. Oral Surg Oral Med Oral Pathol Oral Radiol Endod. 2011;112(3):322-7.

19. Kaufman LB, Setiono TK, Doros G, Andersen S, Silliman RA, Friedman PK, et al. An oral health study of centenarians and children of centenarians. J Am Geriatr Soc. 2014;62(6):1168-73.

20. National Institute of Dental and Craniofacial Research. 2013. Retrieved from https://www.nidcr.nih.gov/research/data-statistics/tooth-loss/seniors?_ga= 2.264044940.1262212392.1542141904-1811719232.1467577796.

21. Hoeksema AR, Spoorenberg S, Peters LL, Meijer H, Raghoebar GM, Vissink A, et al. Elderly with remaining teeth report less frailty and better quality of life than edentulous elderly: a cross-sectional study. Oral Dis. 2017;23(4):526-36.

22. Costa S, Martins C, Pinto M, Vasconcelos M, Abreu M. Socioeconomic factors and caries in people between 19 and 60 years of age: an update of a systematic review and meta-analysis of observational studies. Int J Environ Res Public Health. 2018;15(8):1775.

23. Kalsbeek $\mathrm{H}$, de Baat C, Kivit MM, de Kleijn-Vrankrijker MW. Mondgezondheid van thuiswonende ouderen 2. Het subjectieve aspect van mondgezondheid. Ned Tijdschr Tandheelkd. 2001;108:16-20.

24. Martin P, Da Rosa G, Siegler IC, Davey A, MacDonald M, Poon LW, et al. Personality and longevity: findings from the Georgia centenarian study. Age. 2006;28(4):343-52

25. Masui $Y$, Gondo $Y$, Inagaki H, Hirose N. Do personality characteristics predict longevity? Findings from the Tokyo centenarian study. Age. 2006;28(4):353-61.

26. Samuelsson S-M, Alfredson BB, Hagberg B, Samuelsson G, Nordbeck B, Brun A, et al. The Swedish centenarian study: a multidisciplinary study of five consecutive cohorts at the age of 100. Int J Aging Hum Dev. 1997:45(3):223-53.

27. Hoeksema AR, Peters LL, Raghoebar GM, Meijer HJA, Vissink A, Visser A. Health and quality of life differ between community living older people with and without remaining teeth who recently received formal home care: a cross sectional study. Clin Oral Investig. 2018.

28. Niesten D, van der Sanden WJ, Gerritsen AE. The impact of frailty on the oral care behaviour and dental service use of elderly people. Ned Tijdschr Tandheelkd. 2015;122(4):210-6.

29. Petersen PE. The world Oral health report 2003: continuous improvement of oral health in the 21 st century-the approach of the WHO global Oral health Programme. Community Dent Oral Epidemiol. 2003;31:3-24. 
30. Visser A, Maarel-Wierink CD van der, Janssens B, Niesten D, Jerković-Ćosić K, Duyck J, Gerritsen A, Hollaar V, Krausch-Hofmann S, Putten GJ van der, Weijenberg RAF, Listl S, Lobbezoo F, Schols JMGA, Bruers JJM.

Wetenschapsagenda mondzorg voor ouderen in Nederland en Vlaanderen. Ned Tijdschr Tandheelkd. 2019;126

\section{Publisher's Note}

Springer Nature remains neutral with regard to jurisdictional claims in published maps and institutional affiliations.

Ready to submit your research? Choose BMC and benefit from:

- fast, convenient online submission

- thorough peer review by experienced researchers in your field

- rapid publication on acceptance

- support for research data, including large and complex data types

- gold Open Access which fosters wider collaboration and increased citations

- maximum visibility for your research: over $100 \mathrm{M}$ website views per year

At $\mathrm{BMC}$, research is always in progress. 